\title{
The Effect of the Tennis Technical Training on Coordination Characterictics
}

\author{
Asuman Sahan and K. Alparslan Erman*
}

Akdeniz University, School of Physical Education and Sports, Dumlupinar Avenue 07058 Campus Antalya, Turkey

\begin{abstract}
The purpose of this study was to investigate the effect of tennis training on balance and hand-eye coordination. We also tried to determine the speed difference of coordination evolution in people who had not previously played ball sports compared with people who had.

There were two groups on our research. The first group consisted of 17 male university students who had already played a ball sport aged 22,11 $\pm 0,98$ year. We chose the subjects by searching for athletes who had trained for a sport branch other than tennis at least 3 days a week for more than 2 years. The second group consisted of 15 male university students who had not previously played a ball sport aged 20,46 $\pm 1,60$ year. We gave each subject eight weeks of tennis training, twice a week, 2 hours per day. No special formative practices concerning balance or coordination were given to the subjects. The subjects were tested with the Flamingo Balance Test, Hand eye coordination test and Tennis Ability Test. The tests were carried out at the beginning ( $4^{\text {th }}$ hour), the middle $\left(16^{\text {th }}\right.$ hour) and the end of our study ( $36^{\text {th }}$ hour).

By statistical analysis of the results of the tests, we can say that for Flamingo Balance Test, recessive hand-eye coordination test and Tennis Ability Test there was a significant difference between the first evaluation and the third evaluation for both groups $(p<0,05)$. Moreover, learning acceleration between $1^{\text {st }}$ and $2^{\text {nd }}(p<0,05)$ evaluation were greater than $2^{\text {nd }}$ and $3^{\text {rd }}$ one $(p>0,05)$. This result supports $2^{\text {nd }}$ purpose of the study. Accordingly, their learning improvement was slowdown in Recessive Hand-eye Coordination and Tennis Ability Tests both of groups.
\end{abstract}

Keywords: Tennis, balance, hand-eye coordination, improvement of learning, motor control.

\section{INTRODUCTION}

Tennis is a dynamic sport game played with a racket and a ball. Success in tennis is defined by several factors. Apart from the social factor, potential capacity, improvable capacity and competition experience can all affect success [1]. Tennis is also one of the sports that need, besides balance and coordination skill, characteristics such as strength, endurance, speed and flexibility [1-5].

Backhand and forehand are the two basic groundstrokes in tennis. Both strokes are accomplished by the activation of complex sequences of muscle activity which incorporate smooth coordination patterns of the trunk and lower extremities [6]. The service and groundstrokes are generally two segment coordination strategies used in tennis. In strokes where power is required, a number of body segments must be coordinated in such a way that a high racquet speed is generated at impact [7].

Motor-skill learning might be especially influenced by preconditions such as endurance, strength, or other motor abilities. For example, learning of the high jump is mainly influenced by strength and learning of fine motor skills by hand-eye coordination [8]. Motor abilities tests (e.g., balance, coordination, eye-hand coordination, and kinesthesis) of young prospects, as well as their skill level in a given

*Address correspondence to this author at the Akdeniz University, School of Physical Education and Sports, Dumlupinar Avenue 07058 Campus Antalya, Turkey; Tel: +90 242 3101783; Fax: +90 242 2271116;

E-mail: ermana@akdeniz.edu.tr sport (e.g., serving in tennis) $[9,10]$. Studies on motor abilities analysis showed that scores on measures of groups of athletes than for corresponding control groups. These findings indicate the presence of systematic differences between elite athletes and nonathletes on motor abilities related to experience in this sport [11].

Recommends the game of tennis to get a good physical workout and improve eye-hand coordination. Functional magnetic resonance imaging finding indicating that cerebellum has a critical role in hand-eye coordination [12]. Many effects such as wind, rough surface or the rotation of the ball can change the ball direction in tennis. Balls never come with the same speed or timing. As the way the ball impacts the racket and the ball speed can change, the handeye coordination gets more important $[1,3-5,13]$.

Blundel, investigated differences in peripheral perception between athletes and nonathletes peripheral vision in tennis players of different sports level, from novice to international players. Peripheral sensitivity was determined using different color lights. Results show that these elite athletes had a significantly wider field of vision than novice athletes with regards to white and yellow. Similarly, Williams and Thirer showed statistically significant differences between athletes playing American football, fencing and tennis vs. nonathletes with regard to the central and peripheral fields of vision. However, in either case it is difficult to determine whether wider peripheral vision was an effect of training, or was perhaps due to the initial selection of the players [14]. Filipcic, determined the relationship of tennis hand-eye coordination, dynamic balance abilities and the competition 
efficiency of young female tennis players. In this study to measure hand-eye coordination during $60 \mathrm{sec}$ ball bounce with racket is used to test (ball bouncing turn about on the face and frame of a racket) [1].

Proprioception is more crucial for tennis because the tennis skills are composed by complex movement demanding high balance ability. In other words, balance is one fundamental ability that tennis player should develop in order to perform better in the court [15].

Racquet work to control the ball's height, direction and speed a groundstroke self-rally drill would consist of the player continuously tapping the ball up after it bounces on the ground (usually sending it just above head level to anticipate the future skill of sending the ball up and over the net). Rather than 'chaining' the skill in sequence (preparation, hit, follow-through), the groundstroke skills would be 'shaped' from the impact point. Here is how you must adjust your feet to organize yourself around a good impact that is at waist level, slightly out front, and a comfortable distance from your body [16].

In a research made the flamingo balance test was used to examine the postulated hypothesis. The result revealed that both groups improved their performance. The experimental group outperformed the control group. The retention trial showed that performance levels for both groups continued to improve; suggesting that familiarization with the test influenced not only performance but learning as well. Exercise scientist who implement psychomotor tests, such as balance test, for evaluative purposes should be aware that performance improvement does not necessary represent changes in individuals' performance, but it may reflect individuals' familiarization with the test [17]. Flamingo balance test was conducted just 3 times (pre, middle and post tests) between 3 weeks interval for both groups in this study.

The purpose of this study was to investigate whether balance and hand-eye coordination can be improved by tennis training. We also try to determine the rapidity difference of evolution between subjects who had not previously done a ball sport and subjects who had. In our study, may have a positive impact on the coordination of tennis training is expected.

\section{MATERIALS AND METHODS}

\section{Subjects}

\section{Groups were used for the research.}

$1^{\text {st }}$ Group: Subjects who had already done a sport played with a ball $(\mathrm{n}=17$; Age: $22,11 \pm 0,98$ years; Height: 176,18 $\pm 6,56 \mathrm{~cm}$; Weight: $68,12 \pm 7,82 \mathrm{~kg}$.). Those subjects must have made a sport, other than tennis, for at least 3 days a week during the last 2 years.

$2^{\text {nd }}$ Group: Subjects who had never done a sport played with ball before $(\mathrm{n}=15$; Age: $20,46 \pm 1,60$ years, Height: 173,6,16 cm; Weight: 68,15 $\pm 8,10 \mathrm{~kg}$.)

All the subjects in the research were male university students.

All the subjects had the same re-count (number of hitting ball), training procedure and practice condition (day and hour).
8 weeks of tennis training were given to the subjects, two days a week and two hours a day. Subjects were attended the training at least $\%$ 75. No special formative practices concerning balance or coordination were given to the subjects. All the technique training was done with the dominant hand. The inclusion criteria of subjects were to be between 20-22 age, male and who had not previously played tennis. Subjects trained before $1^{\text {st }}$ test to use to ball and racket.

\section{Training Procedure}

Subjects were trained as following procedures;

\section{From $1^{\text {st }}$ Hour to $4^{\text {th }}$ Hour (Cognitive Stage- $1^{\text {st }}$ Test)}

- $\quad$ Feeling, perceiving and recognizing to the ball.

- $\quad$ Some games related with tennis.

- Introduction the basic tennis techniques.

- $\quad$ From $5^{\text {th }}$ hour to $20^{\text {th }}$ hour (associative stage- $2^{\text {nd }}$ test).

- $\quad$ Teaching the basic tennis techniques (Ground strokes, volleys and services).

- Variations of some simple techniques (Spinning the ball).

- $\quad$ Small rallies and matches in the service court.

From $21^{\text {st }}$ hour to $36^{\text {th }}$ hour (autonomous stage- $3^{\text {rd }}$ test).

- $\quad$ Targeting the balls some special points (e.g. to the baseline, cross-court, down-the-line).

- Variations of some complex techniques (drop shot, passing shot, lob e.g.).

- $\quad$ Rallies and single or double matches in all court.

\section{Applied Tests}

Flamingo Balance and Hand-eye coordination measurements are more important to learning tennis [18].

\section{Flamingo Balance Test (FBT)}

The Flamingo balance machine was $50 \mathrm{~cm}$ long, $4 \mathrm{~cm}$ high and $3 \mathrm{~cm}$ wide. To prevent the balance machine from moving, its two extremities were supported by $15 \mathrm{~cm}$ height and $2 \mathrm{~cm}$ width beams. We asked the subjects to stay on the balance beam with a preponderant leg. The recessive hand was holding the recessive leg at the back of the body. The 60 seconds period started at the time the subjects held their wrists. The timing was stopped each time the subjects let go of their wrist or lost balance and touched the ground with the recessive leg. The one carrying out the test helped the subjects to get to their former position. After assuring stability the timing restarted. The test was being redone until a period of 60 seconds was completed. Every fall was recorded. The number of point count was on how little the subject lost balance $[18,19]$.

\section{Hand-Eye Coordination Test (HECT)}

The subjects made their balls rebound on the rackets for lapses of time of one minute each with the right and the left hand. The test started with the dominant hand and then with the recessive one and this for one minute each. The ball should pass the head level at each rebound. The number of 
falling balls was counted for each dominant and recessive hand. The number of point count was on how little the subject let down the ball [1].

\section{Tennis Ability Test (TAT)}

The subjects stay one metre away from the farthest line with their racket in their hand. The test maker took up position on the other side of the net on the "T" line. The test maker sent alternately $5 \times 11=55$ balls to the right and the left side of the subject. 1,5 metres above the net was suspended an outstretched rope parallel to the net. Numbers were written on the ground of the court. Those numbers meant points and the biggest point was five. The subjects tried to throw the balls between the rope and the net to the highest point. The balls falling into the service box were worth 1 point. The back court was divided into 4 equal parts and from those parts to the farthest line; the scores were alternately worth $2,3,4$ and 5 points. The point on which the ball falls was written in the subject's schedule. The subjects had three minutes to rest between each 11 balls. The balls passing above the outstretched rope, falling out of the court or being stopped by the net counted 0 points.

The development in learning the motor skill comes from the quantitative part of the movement. This development's main topic is to accomplish the movement. The movement made can first be defined by the 3 stage analysis nerve system. The research showed that those stages were; the movement planning, transferring information to the muscles and application. Motor action can be evaluated with; a) error b) timing and speed c) the size of the movement $d$ ) performance on secondary task. During the basic performance you can make more than just one task, as a secondary task physiological evaluation can also be made [19]. For that reason evaluations from the rebounding ball test, to determine the hand-eye coordination, and the Flamingo balance test, to determine the static balance, were incorrect in our study. Performance on the secondary task was used as an evaluation means during the Tennis Ability Test (Fig. 1).

\section{Statistical Analyse}

Normality Test was applied to all measured parameters. Repeated Measure ANOVA and Kruskall Wallis statistical analysis were used to determine within group differences. If the data normally distributed, we applied parametric statistical methods (paired or independent $t$ test) on the contrary nonparametric statistical methods (Mann-Whitney U or Wilcoxon).

\section{RESULTS}

\section{Balance}

There were no significant differences between three measures both of groups in balance measurement $\left(1^{\text {st }}\right.$ group; $\mathrm{p}<0,00,2^{\text {nd }}$ group, $\left.\mathrm{p}<0,03\right)$ according to Repeated Measure ANOVA.

During the balance evaluations, both of the groups showed a significant difference between the $1^{\text {st }}$ evaluation and the $3^{\text {rd }}$ one $(p<0,01)$. There were no significant evaluation differences between the two groups $(p>0,05)$ (Table 1).

\section{Hand-Eye Coordination}

There were no significant differences between three measures both of groups in Hand-eye Coordination measurement $\left(1^{\text {st }}\right.$ group; $\mathrm{p}<0,64,2^{\text {nd }}$ group, $\mathrm{p}<0,04$ for DHECT, $1^{\text {st }}$ group; $p<0,00,2^{\text {nd }}$ group, $p<0,04$ for RHECT) according to Repeated Measure ANOVA.

As a result for the DHECT (Dominant Hand Eye Coordination Test), we can say that there were no significant differences from the 1 st to the $3^{\text {rd }}$ evaluation for both of the groups $(p>0,05)$. There were no significant evaluation differences between the two groups $(p>0,05)$. As a result for

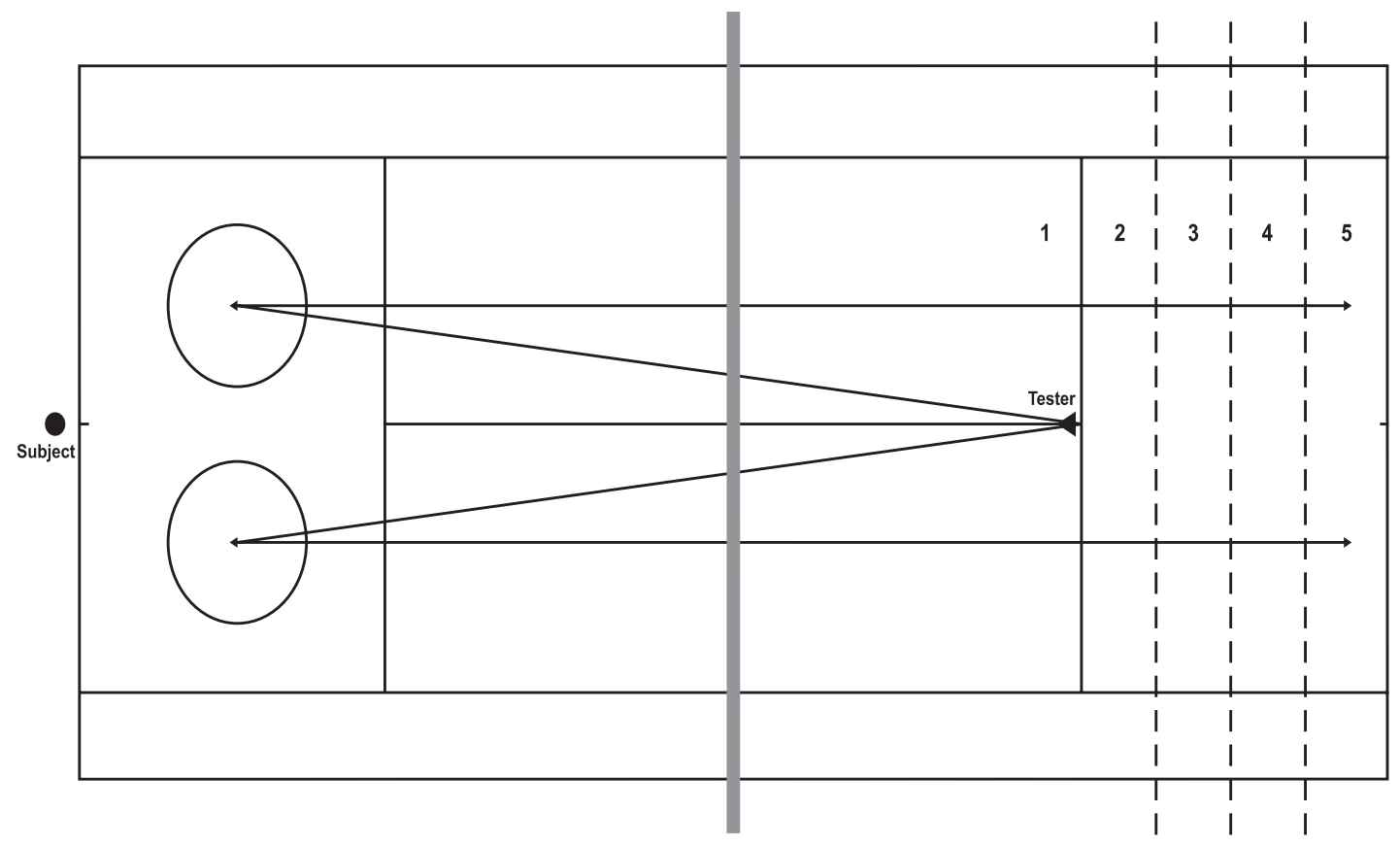

Fig. (1). Tennis ability test application. 
Table 1. Flamingo Balance Test Results

\begin{tabular}{|c|c|c|c|c|c|c|c|}
\hline & Groups & $\mathbf{1}^{\text {st }}$ Measurement & $\mathbf{p}$ & $\mathbf{2}^{\text {nd }}$ Measurement & $\mathbf{p}$ & $\mathbf{3}^{\text {rd }}$ Measurement & $\mathbf{1}^{\text {st }} \mathbf{M} . \mathbf{- 3}^{\text {rd }} \mathbf{M} . \mathbf{p}$ \\
\hline \hline \multirow{2}{*}{$\begin{array}{c}\text { Number } \\
\text { of Errors }\end{array}$} & 1. group & $3,59 \pm 3,81$ & 0,05 & $2,24 \pm 2,46$ & 0,55 & $1,88 \pm 2,39$ & $0,00 * *$ \\
\cline { 2 - 8 } & $\mathbf{P}=$ & 0,86 & & 0,63 & & 0,61 & $0,01 *$ \\
\cline { 2 - 8 } & 2. group & $2,93 \pm 2,02$ & 0,23 & $2,33 \pm 1,80$ & 0,33 & $2,07 \pm 1,91$ & 0 \\
\hline
\end{tabular}

${ }^{*} \mathrm{p}<0,05 * * \mathrm{p}<0,01$.

the RHECT (Recessive Hand Eye Coordination Test), there was a significant difference for both of the groups between the $1^{\text {st }}$ and the $3^{\text {rd }}$ evaluations $(\mathrm{p}<0,05)$ (Tables 2 and $\left.\mathbf{3}\right)$.

\section{Tennis Ability Test}

There were no significant differences between three measures both of groups in Tennis Ability measurement $\left(1^{\text {st }}\right.$ and $2^{\text {nd }}$ groups; $\left.\mathrm{p}<0,00\right)$ according to Repeated Measure ANOVA.
As a result for the TAT, there was a significant difference for both of the groups between the $1^{\text {st }}$ and the $3^{\text {rd }}$ evaluations $(\mathrm{p}<0,01)$ (Table 4).

\section{DISCUSSION AND CONCLUSIONS}

Solving problems concerning the movement control of the Central Nervous System (CNS) is called the "Bernstein Problem" [20]. Bernstein had worked on how to solve the many problems there are about motor control of CNS [21]. Furthermore, during his motor control research, he studied

Table 2. Dominant Hand-Eye Coordination Test Results

\begin{tabular}{|c|c|c|c|c|c|c|c|}
\hline & Groups & $\mathbf{1}^{\text {st }}$ Measurement & $\mathbf{p}$ & $\mathbf{2}^{\text {nd }}$ Measurement & $\mathbf{p}$ & $\mathbf{3}^{\text {rd }}$ Measurement & $\mathbf{1}^{\text {st }} \mathbf{M . - 3} \mathbf{3}^{\text {rd }} \mathbf{M} \cdot \mathbf{p}$ \\
\hline \hline \multirow{2}{*}{$\begin{array}{c}\text { Number of } \\
\text { Errors }\end{array}$} & 1. group & $0,59 \pm 1,33$ & 0,07 & $0,06 \pm 0,24$ & 0,57 & $0,12 \pm 0,33$ & 0,13 \\
\cline { 2 - 8 } & $\mathbf{P}=$ & 0,13 & & $0,02 *$ & & 0,49 & $0,40 \pm 1,06$ \\
\cline { 2 - 8 } & 2. group & $1,07 \pm 1,62$ & 0,31 & $0,67 \pm 1,11$ & 0,10 & 0,10 \\
\hline
\end{tabular}

${ }^{*} \mathrm{p}<0,05 * * \mathrm{p}<0,01$.

Table 3. Recessive Hand-Eye Coordination Test Results

\begin{tabular}{|c|c|c|c|c|c|c|c|}
\hline & Groups & $\mathbf{1}^{\text {st }}$ Measurement & $\mathbf{p}$ & $\mathbf{2}^{\text {nd }}$ Measurement & $\mathbf{p}$ & $\mathbf{3}^{\text {rd }}$ Measurement & $\mathbf{1}^{\text {st }}$ M.-3 ${ }^{\text {rd }} \mathbf{M} . \mathbf{p}$ \\
\hline \hline \multirow{3}{*}{$\begin{array}{c}\text { Number } \\
\text { of error }\end{array}$} & 1 group & $1,35 \pm 1,69$ & $0,01^{*}$ & $0,29 \pm 0,47$ & 0,48 & $0,18 \pm 0,53$ & $0,01^{*}$ \\
\cline { 2 - 8 } & $\mathrm{p}=$ & 0,14 & & $0,03 *$ & & 0,07 & $0,07 \pm 1,10$ \\
\cline { 2 - 8 }
\end{tabular}

Improvement differences between groups on hand-eye coordination

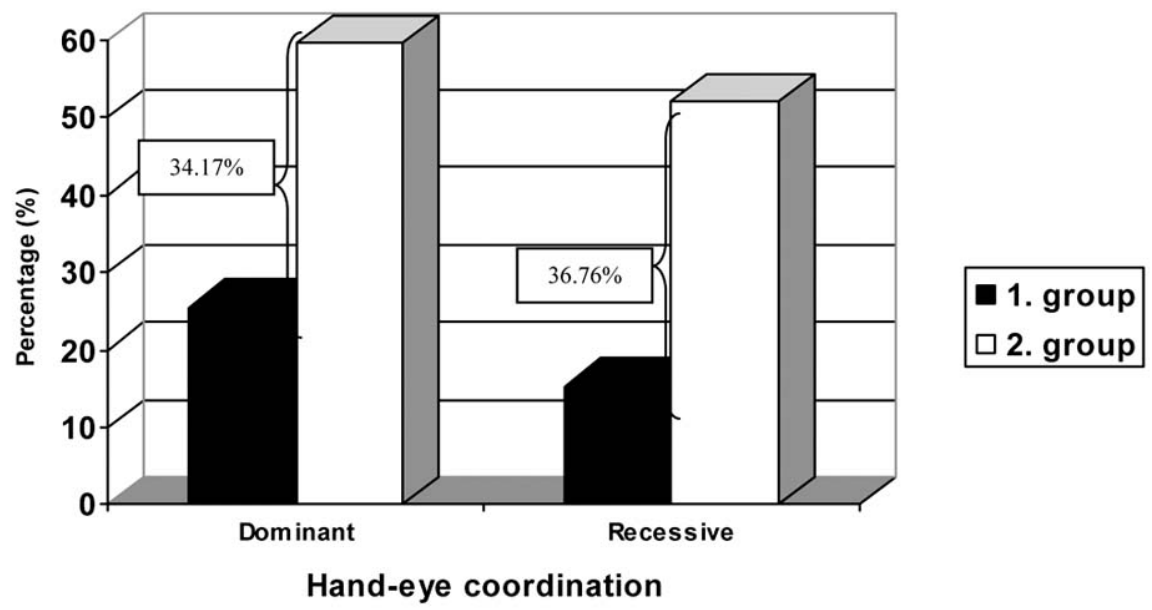

Fig. (2). Comparison of the hand-eye coordination improvement differences between dominant and recessive hand. 
Table 4. Tennis Ability Test Results

\begin{tabular}{|c|c|c|c|c|c|c|c|}
\hline & Groups & $\mathbf{1}^{\text {st }}$ Measurement & $\mathbf{p}$ & $\mathbf{2}^{\text {nd }}$ Measurement & $\mathbf{p}$ & $\mathbf{3}^{\text {rd }}$ Measurement & $\mathbf{1}^{\text {st }} \mathbf{M . - 3} \mathbf{3}^{\text {rd }} \mathbf{M} . \mathbf{p}$ \\
\hline \hline \multirow{2}{*}{$\begin{array}{c}\text { Percentage } \\
(\%)\end{array}$} & 1. group & $27,48 \pm 8,40$ & $0,00^{* *}$ & $34,82 \pm 7,48$ & 0,47 & $35,76 \pm 5,41$ & $0,00^{* *}$ \\
\cline { 2 - 8 } & $\mathbf{p}=$ & 0,11 & & 0,58 & & 0,62 & 0,02 \\
\cline { 2 - 8 }
\end{tabular}

what were the physical parameters controlled by CNS [24]. As a conclusion for Bernstein;

- $\quad$ The movement control systems have a hierarchical structure at one or two level.

- During the movement of the feedback rotation, adjustment is made for low or high level.

- Time lost during feedback rotation is unavoidable because open rotational models necessitate presentiment.

- The insufficiency of the motor system causes the movement control systems' indefiniteness [22].

- As the movement period is short, this is one of the most important factors which increase the quantity of errors [22].

Very quick movement (200-300 ms), is first of all controlled by the neuromuscular pattern's activities [21]. In tennis, during the service return, the player's response time is very short. For beginners it is also important to make many decisions very quickly $(200-300 \mathrm{~ms})$.

The nerve system regulates skilfully the mechanical degradations that come un-welcomed during the movement [22]. The problems that may occur during the movement can be anticipated. Those internal processes prevent the muscles from too much movement during the action [22]. The processes that rule the spatiotemporal action pattern by controlling each muscles is called the Kohnstamm coordination. Coordination means to rule the movements automatically and voluntarily [21]. Tennis is a sport that needs, beside balance and coordination ability, some conditional particularities [23-25].

The movement control is about the cortical space's function and organisation. Each pre-motor space has a potential effect on the control of the movement. The movement control is not only about the pre-motor cortex activity but also about the spinal cord activity. If the low programs that participate in the movement are too much, this will hinder the perfection of the multi-articulations performance because in multi-articulation movement the response time is longer and the response elasticity is less. In voluntary movement the motor cortex focus on the standard sensory motor clue because sensory motor warnings can change quickly and are flexible [26]. The body parts have a mechanism able to correct the errors due to the relation to the force and torque. As coordination means to control many articulations, it is called the units' synergy [22]. During tennis technique practices, the arms, body and legs' muscles must contract in a co-ordinated manner. That means multiarticulation movement control. As a result the probability to make an error when we start learning or practicing tennis techniques is very high because multi-articulation movement organisation affects negatively a perfect movement. Concerning that point the tennis learner may have two principal problems. 1) Each movement's low part should be correctly applied and 2) the response time should match with the warning.

It is said in books and articles that professional tennis players always use their body rotation correctly and produce force and control perfectly for their balance. Those are the most similar characteristics of professional tennis players $[23,27,28]$. To be sure of hitting the ball the way the player wants it, the player must maintain a balanced position and must maintain it.

For the mechanists, balance is explicable with in two words, stable and unstable. Static balance means to come back to the balance position we have before any perturbations. However, the organism can become stable again if the power used during the action to gain the balance back is bigger than the perturbation power. The small period of time during which the organism tries to gain back its stability after the perturbation is called dynamic balance [29]. The tennis student must, during the training, constantly transfer weight. By doing that, the tennis student perturbs balance and it always has to be regained. The tennis student always has to try to regain balance.

At the basic point of voluntary postural movement control and reaction stand MMS and neurophysiology mechanisms. As the new learned action breaks down the coordination, the motor cortex function breaks down as well [29]. The synchronisation between coordination, posture and movement means control. The postural regulations of subjects who put their arms in the air and so became instable. As a result they determined that the balance and the segments should stay in accordance during arm movements [21]. Due to this information, a person learning tennis techniques will constantly loose his balance and then that person makes postural regulations. As a person learns tennis techniques, the appearing perturbations and control mechanisms may help to improve balance.

At any articulation movement, the other segments also participate in the movement. It is not easy to explain the parallel control mechanism standing between balance and movement control during coordination. There is a big chance that a single mechanism controls both tasks [21]. The centre of gravity can be controlled by the body's fractional position. This regulation is done by the element coordination that helps contraction and this coordination is provided by the warnings coming from the primary motor cortex [22]. We made the observation in our study that the subjects improve their balance characteristics by doing tennis training $(p<0,05)$. During training the balls were thrown to the subjects from different distances and at different speeds. The 
subjects had to make a step to hit the balls. We think that doing such exercises ameliorate the balance characteristics. As the results of our study show and as noted by Groppell and Hölm, tennis technique training improves balance [24, 29].

When the organism is learning another task which needs coordination, instead of applying new attitude rules, it prefers to use the basic sensory motor facilities learned before [30]. That is the reason we thought that sport experience would be an important factor in our study and that it would be easier for those who had sport experience to learn the tennis techniques. However, our study shows us that having done a ball sport before do not affect tennis techniques or coordinative characteristics' evolution.

Filipčič, made a study on 96 young female tennis players aged 13-14. He found a significant relation between the players' specific motor ability, which was tested by the hand-eye coordination test, and competition productivity ( $\mathrm{p}$ $=0,018)$ and between dynamic balance and competition productivity $(p=0,010)[6]$. In our study, we found during the evaluation that both groups made significant progress in dominant hand-eye coordination. However, we could not find a big difference between the evaluations $(p>0,05)$. Even if the group which had don e ball sports before had better results than the other group, our study shows us that the group which had made sports before showed 25,53\% amelioration, whereas the other group showed 59,70\% amelioration. For the recessive hand-eye coordination we found amelioration between the evaluations for both groups. There was also a significant difference between the two groups $(\mathrm{p}<0,01)$. After 8 weeks of tennis training, the recessive hand-eye coordination had improved by $15,38 \%$ for the first group and 52,14\% for the second group. On the basis of that result we can say that reactive tennis technique training contributes (especially for the group which did not do a sport before) to the improvement of balance and handeye coordination.

We can see (Fig. 2) that the progress difference of the first and second groups is greater in recessive hand-eye coordination. (Dominant hand-eye: $34,17 \%$, recessive handeye: $36,76 \%$ ). There were no big progress differences (for either group) in dominant hand-eye coordination. If we compare this to the fact that the subjects made significant progress with recessive hand-eye coordination, we can say that tennis technique training made with the dominant hand helps recessive hand-eye coordination to progress. Here it can be based on the CNS integrated action understanding characteristic of the hand-eye coordination better than the transfer effect. During the trainings, making the ball rebound with the recessive hand (hand-eye coordination) training was not done but we remarked that the subjects improved their recessive hand-eye coordination better than dominant handeye coordination. This surprising result may prove that the right hand is the one making the motor program and that the left hand is active. Accordingly; 1) motor program and integrated systems were improved by tennis training. 2) the hand-eye inter-muscles and intra-muscle coordination was already improved with the dominant hand but the recessive hand-eye inter-muscles and intra-muscles coordination characteristics was not fully developed before. 3) We can say that, the development showed in the motor program's tennis technique training did not help the dominant hand to improve but for the recessive hand, even this small progress made a meaningful development.

A person playing tennis as a reactive objective will show progress in hand-eye coordination and static balance characteristics and so will increase quality of life. We need hand-eye coordination for driving, eating, doing sport, working and many other activities [31]. Many coaches want their tennis players to play with high performance. In reality, tennis coaches should be aware that tennis technique training is not just about the players' performance, but also about innumerable small details that make quality of life better.

When a motor is in action, two or more limbs join the movement. During the movement, each limb must, first of all, show its suitable action pattern. Then, different limbs must do the movement at the most suitable time [23]. In tennis training, the tennis player must control every limb and at the right time try to make the best movement figure.

Learning opened abilities is different from learning closed abilities. Opened abilities are performed when you respond to a warning that cannot be anticipated. On the other hand, closed abilities are the ones that can be anticipated, so it is possible to anticipate the environmental and the consequential performance changes. The transition between opened and closed abilities of the movement is made at a different time and in a different way [32, 33].

Consequently, while learning tennis techniques, the tennis player faces many difficulties in bringing the ball and the racket together. For this task the player needs opened ability. But as the player repeats its action to bring the ball and the racket together, the ability will become a closed activity and the player will start to guess the ball's variations.

As a result, during the tennis ability test, both of the groups show significant progress between the evaluations $(\mathrm{p}<0,01)$. This result tells us that after 8 weeks ( 32 hours) of tennis technique training, the subjects showed better performance. We can say that the subjects learned how to play tennis.

If training program is well-programmed, it helps participants gain optimum performance [34].

It is normal to see a linear relation between muscle coordination and hand-eye coordination's evolution and tennis ability test performance evolution of subjects because the subjects try to hit the balls, coming from the opposite side, with their rackets and direct them on a specific target. Coordinative characteristics are needed to do such a task.

This research has found the tennis technical training does improve balance and recessive hand-eye coordination in young man between ages 20-22 years. Besides, the finding this research is tennis technical training does not effective to improve dominant hand-eye coordination. The results of the dominant hand, with fine skills, coordinative feature completing rapid development phase but developing recessive hand to hand-eye coordination yet be in phase due to the rapid development may have.

Moreover, learning acceleration between $1^{\text {st }}$ and $2^{\text {nd }}$ evaluation were grater than $2^{\text {nd }}$ and $3^{\text {rd }}$ one. This result 
supports $2^{\text {nd }}$ purpose of the study. Accordingly, their learning improvement was slowdown in Recessive Hand-eye Coordination and Tennis Ability Tests both of groups.

\section{REFERENCES}

[1] Filipcic A, Filipcic T. The relationship of tennis-specific motor abilities and the competition efficiency of young female tennis players. Kinesiology 2005; 372: 167-72.

[2] Groppeln JL, Loehr JE, Melville DS, Quinn AM. Science of coaching tennis. USA: Hum Kin 1989.

[3] Grosser M, Schörnborn R. Competitive tennis for young players. Oxford: Meyer \& Meyer 2002.

[4] Lafont D. Six good reasons to keep your eye of the ball. ITF Coaching Sport Sci Rev 2008; 15(44): 5-6.

[5] Schöborn R. Advanced techniques for competitive tennis. Oxford: Meyer\&Meyer Sport 2000.

[6] Mavvidis A, Koronas K, Riaganas C, Metaxas T. Speed differences between forehand and backhand in intermediate-level tennis players. Kinesiology 2005; 37(2): 159-63.

[7] Elliott B. Biomechanics and tennis. Br J Sports Med 2006; 40: $392-$ 6.

[8] Voelcker RC. Motor-skill learning in older adult, a review of studies on age-related differences. Eur Rev Aging Phys Acta 2008; 5:5-16.

[9] Lidor R, Cote J, Hackfort D. ISSP position stand: to test or not to test? the use of physical skill tests in talent detection and in early phases of sport development. USEP 2009; 7(2): 131-46.

[10] Ericsson I. To measure and improve motor skills in practice. Int $\mathbf{J}$ Ped Obesity 2008; 3: 21-7.

[11] Kioumourtzoglou E, Derri V, Mertzanidou O, Tzetszis G. Experience with perceptual and motor skills in rhythmic gymnastics. Per Mot Skill 1997; 84(3), 1363-72.

[12] Iacoboni M. Playing tennis with the cerebellum. Nat Neurosci 2001; 4(6): 555.

[13] Schmidt RA, Lee TD. Motor control and learning. USA: Hum Kinet 2005.

[14] Ziwierko T. Differences in peripheral perception between athletes and nonathletes. J Hum Kinet 2007; 19: 53-62.

[15] Malliou VJ, Malliou P, Gioftsidou A, et al. Balance exercise program before or after a tennis training session? J Back Musculoskelet Rehab 2008; 21(2), 87-90.
[16] Elderton W. Progressive tennis: 5-7 year old development. ITF Coaching Sport Sci Rev 2009; 16(47): 5-6.

[17] Tsigilis N, Theodosiou A. The influence of multiple administration of psychomotor test on performance and learning. Strength Cond Res 2008; 22(6), 8.

[18] Council of Europe. Testing physical fitness eurofit. Strasbourg: France 1983.

[19] Shmidt RA, Timothy DL. Motor control and learning. USA: Hum Kinet 2005.

[20] Latash ML. Progress in motor control. USA: Hum Kinet 2004; vol. 3.

[21] Latash ML. Progress in motor control. USA: Hum Kinet 1998; vol. 1.

[22] Latatsh LM. Control of human movement. USA: Hum Kinet 1993.

[23] Crespo M, Higueras J. World class tennis technique book. USA: Hum Kinet 2001.

[24] Groppeln JL, Loehr JE, Melville DS, Quinn AM. Science of coaching tennis. USA: Hum Kinet 1989.

[25] Unierzyski P, Crespo M. Review of modern teaching methods for tennis. Revista İnternacional de Ciencesas del Deporte 2007; 7(3): $1-10$.

[26] Alexa R, Elilon V. Motor cortex in voluntary movements. USA: CRC Press 2005.

[27] Reid M, Quinn A, Crespo M, Eds. Strength and conditioning for tennis. London: ITF 2003; p. 272.

[28] Höhm J. Tennis play to win the Czech way. Toronto: Sports Book Publisher 1987.

[29] Latash ML. Progress in motor control. USA: Hum Kinet 2002; vol. 2.

[30] Sailer U, Flanagan JR, Johansson RS. Eye-hand coordination during learning of a novel visuomotor task. J Neurosci 2005; 25(39): 8833-42.

[31] Crawford JD, Medendorp WP, Marotta JJ. Spatial transformations for eye-hand coordination. J Neurophysiol 2004; 92: 10-9.

[32] Kimmet D. Physical education theory and practice. Australia: Macmillan 1986.

[33] Schmidt RA, Lee TD. Motor control and learning. USA: Hum Kinet 2005.

[34] Kosvacs MS. Applied physiology of tennis. Br J Sports Med 2006; 40: 381-6. 